\title{
Otorhinolaryngological Findings in Patients from Southwestern Colombia with Clinical, Enzymatic and Molecular Diagnosis of Mucopolysaccharidosis II, IV-A and VI \\ Journal of Inborn Errors of Metabolism \& Screening 2020, Volume 8: e20190006 DOI: 10.1590/2326-4594-JIEMS-2019-0006
}

\author{
Lina Johanna Moreno Giraldo ${ }^{1,2,3,4}$, Daniela Arturo-Terranova ${ }^{1,4}$, \\ José María Satizábal Soto1,2,4
}

\begin{abstract}
Mucopolysaccharidosis is characterized by excessive accumulation of glycosaminoglycan sulfate in organs and tissues. Otorhinolaryngological and upper respiratory tract pathologies are among the earliest clinical manifestations. We realized a retrospective study of clinical and otorhinolaryngologic findings of 35 patients diagnosed with MPS type II, IV-A and VI of the Colombian southwest. As a result, we found that $64 \%$ of the patients evaluated had hearing loss, $11.3 \%$ had hypertrophy of the tonsils, $17.10 \%$ short neck and macroglossia. Additionally, $47.8 \%$ of the patients presented otitis media. $20 \%$ received treatment with hearing aids. no patient reported otosclerosis or tinittus. In patients with different types of MPS, there is a high frequency and progressive tendency to suffer audiological losses and recurrent infections, so it is important an opportune diagnosis, permanent monitoring and adequate therapy to avoid the repercussion of the pathology in the quality of life of patients.
\end{abstract}

\section{Keywords}

hearing loss, mucopolysaccharidosis, otitis media, otorhinolaryngological findings.

\section{Background}

Mucopolysaccharidosis (MPS) forms a group of inherited metabolic disorders caused by the specific deficiency of a hydrolase responsible for a step in the degradation of mucopolysaccharides or glycosaminoglycans (GAG) due to mutations in the genes that code for the enzymes involved in said degradation[1]; actually, four main GAGs are known: chondroitin sulfate, dermatan sulfate, heparan sulfate and keratin sulfate with variable localization in the body[2,3]; and its accumulation within the connective tissue results in a wide range and variety of clinical effects that depends specifically on the enzyme deficiency.[4] Thus, based on this enzyme deficiency, 7 different forms of MPS have been assigned: MPS I (Hurler's syndrome)[5] MPS II (Hunter's syndrome)[6] MPS III (Sanfilippo's syndrome)[7] MPS IV (Morquio syndrome)[8] MPS VI (Maroteaux-Lamy syndrome)[9], MPS VII (Sly disease)[10] and MPS IX (Natowicz syndrome)[11]; Each of these syndromes has a subtype and in total eleven enzymatic defects have been detected. All MPS are inherited as an autosomal recessive trait except Hunter syndrome (MPS II) which is a disease linked to the X chromosome[12].

The clinical manifestations are extremely heterogeneous, with very mild manifestations of late development, without cognitive disorders, and high life time expectation to very severe cases of

\footnotetext{
${ }^{1}$ Universidad del Valle, Cali, Colombia

2 Universidad Santiago de Cali, Cali, Colombia

${ }^{3}$ Universidad Libre, Cali, Colombia

${ }^{4}$ Universidad del Valle, Research Group Congenital Diseases Of Metabolism, Cali, Colombia
}

Received June 22, 2019, and in revised form December 23, 2019. Accepted for publication January 09, 2020.

\section{Corresponding Author:}

José Maria Satizábal Soto, Universidad del Valle, Cali, Colombia.

Email: jose.satizabal@correounivalle.edu.co 
early onset, rapidly progressive, with neural degeneration and limited capabilities in life[13]; Depending on the MPS subtype, retardation of growth and development, skeletal abnormalities, heart valve problems, hepatosplenomegaly, vision and hearing deficits and upper airway obstruction are observed.[14] Generally, the area of the head and neck are greatly affected by the early stages of the disease, so that the treating physician can see children with MPS before the diagnosis of systemic disease.[15]

The disease may involve nervous, skeleton, digestive, cardiac, superior and inferior respiratory systems presenting different levels of severity in an independent manner.[13] Regarding otorhinolaryngological problems associated with MPS, it has been determined that the accumulation of GAGs in the upper respiratory tract produces upper respiratory infections and otitis media (OM)[16], hearing loss, otorrhea, , hypertrophy of tonsils and adenoid, recurrent rhinosinusitis, speech disorders, snoring, oral breathing and nasal obstruction[13]; also, it has been related to hearing loss with a neurosensory component and progressive over time, in addition to short neck (SN) and odontoid hypoplasia[16] hypertrichosis, acetabular dysplasia and contracted joints.[17]

Specifically about MPS II ( OMIM 309900), IV ( OMIM 253000) and VI ( OMIM 253200), investigation has been carried out that allows us to understand many aspects of hearing loss. It is known that in patients with MPS II have a number of abnormalities that impact upon their ability to hear. Frequent upper respiratory infections, chronic otitis media with effusion (glue ear), and recurrent episodes of acute $\mathrm{OM}$ are a common and early signs of the disorder, in part reflecting adenotonsillary hypertrophy and subsequent eustachian tube dysfunction[14]. On the other hand, based on a few studies, it is suggested that hearing loss in MPS IVA is bilateral and progressive in general, similar to other MPS types[18,19], and its severity ranges from mild to moderate. Many of the adult patients with MPS IV exhibit permanent or severe hearing loss[20], and finally, although MPS VI is characterized by normal intellectual development with normal hearing in early infancy, it is important to examine for hearing loss, especially when an infant with this disease shows developmental delay.[21]

For the patients affected with this disease, enzyme replacement therapy (ERT) has been implemented, which consists in supplying the patient with the exogenous protein that is being abnormally synthesized in their organism[4]; This therapy has been shown to be effective in decreasing the excretion of urinary GAGs, improving performance on the walk test and increasing forced vital capacity. In addition, organomegaly decreases, left ventricular hypertrophy and improves the range of joint mobility. [22] For the treatment of otorhinolaryngological failures, the efficacy of ERT in airway permeable maintenance, the reduction of obstruction (tonsillectomy and adenoidectomy) has been reported[23] and the effectiveness in reducing respiratory arrest related to the dream[24]; also to present improvement of the recurrent infections, rhinorrhea, and general respiratory status, expressive and significant improvement of the hearing loss, tympanometric curve pattern, sleep disorders, macroglossia and tonsils and adenoid hypertrophy.[13].

This article describes and characterizes the otorhinolaryngological manifestations found in a group of 35 patients diagnosed with MPS in southwestern Colombia.

\section{Methods}

Retrospective study of the clinical and otolaryngological findings of 35 patients (18 men and 17 women) from Southwestern Colombia with clinical, enzymatic and molecular diagnosis of Mucopolysaccharidosis II, IV-A and VI, with ages between 2 and 60 years. We include results of different evaluations reported in the patient's medical records, taking into account the type of MPS, sex, age at the last visit, audiological tests, audiometry test according to their age, polysomnography study, language changes and report of hearing treatments.

\section{Inclusion Criteria}

We included patients with MPS type II, IV-A y VI of all ages who had a report of hearing problems, any surgery or medical otolaryngology. Patients and relatives who signed the respective consent and assent informed.

\section{Exclusion Criteria}

6 patients who did not have otolaryngology information.

\section{Results}

The otorhinolaryngological results showed that for the three types of MPS studied (II, IV-A and VI), hearing loss and OM were the most frequent diagnoses found, occurring in a large percentage of the cases evaluated (Figure 1). $44 \%$ of patients with MPS IV reported according to the medical history, changes in language since the onset of symptoms.

Approximately $65.64 \%$ of the patients evaluated according to the types of MPS, presented hearing loss, whether it was mild conductive or bilateral sensorineural, $11.3 \%$ had hypertrophy of the tonsils, $17.10 \%$ diagnosed with a SN. 3 patients who presented OSAHS were found through polysomnography $(8,5 \%)$ (Table 1$)$ in general the parameters associated with polysomnography were low with respect to the control; finally, $17.1 \%$ of the patients presented OM (Chronic or acute) (Table 2). In the case of those affected by MPS II, the incidence of OM was reported in 33\%, and for MPS IV-A and VI it occurred in $12.5 \%$ and $20 \%$ respectively (Table 3). Language changes associated with high percentage diagnosis were reported (Figure 2).

As for the problems related to the respiratory tract and hearing problems, there is a relationship between the $\mathrm{SN}$ and apnea with bilateral sensorineural Hearing loss mild and conductive hearing loss (Table 3 ).

The results were detailed by type of MPS as follows: 
Table 1. reference values for polysomnography study and reported data.

\begin{tabular}{lcc}
\hline Parameters & Standar Values & Reported Data for OSAHS \\
\hline TST $(\mathrm{h})$ & $\geq 6 \mathrm{~h}$ & $\leq 5 \mathrm{~h}$ \\
Sleep efficiency & $\geq 80 \%$ & $60-78 \%$ \\
REM sleep (\% TST) & $15-30 \%$ & $8-12 \%$ \\
Slow wave sleep (\% TST) & $10-40 \%$ & $43 \%$ \\
Apnea Index (N / h) & $\leq 1$ & - \\
PetCO2 Peak & $\leq 53$ & - \\
Nadir SatO2 & $\geq 92 \%$ & $2-4 \%$ \\
\hline
\end{tabular}

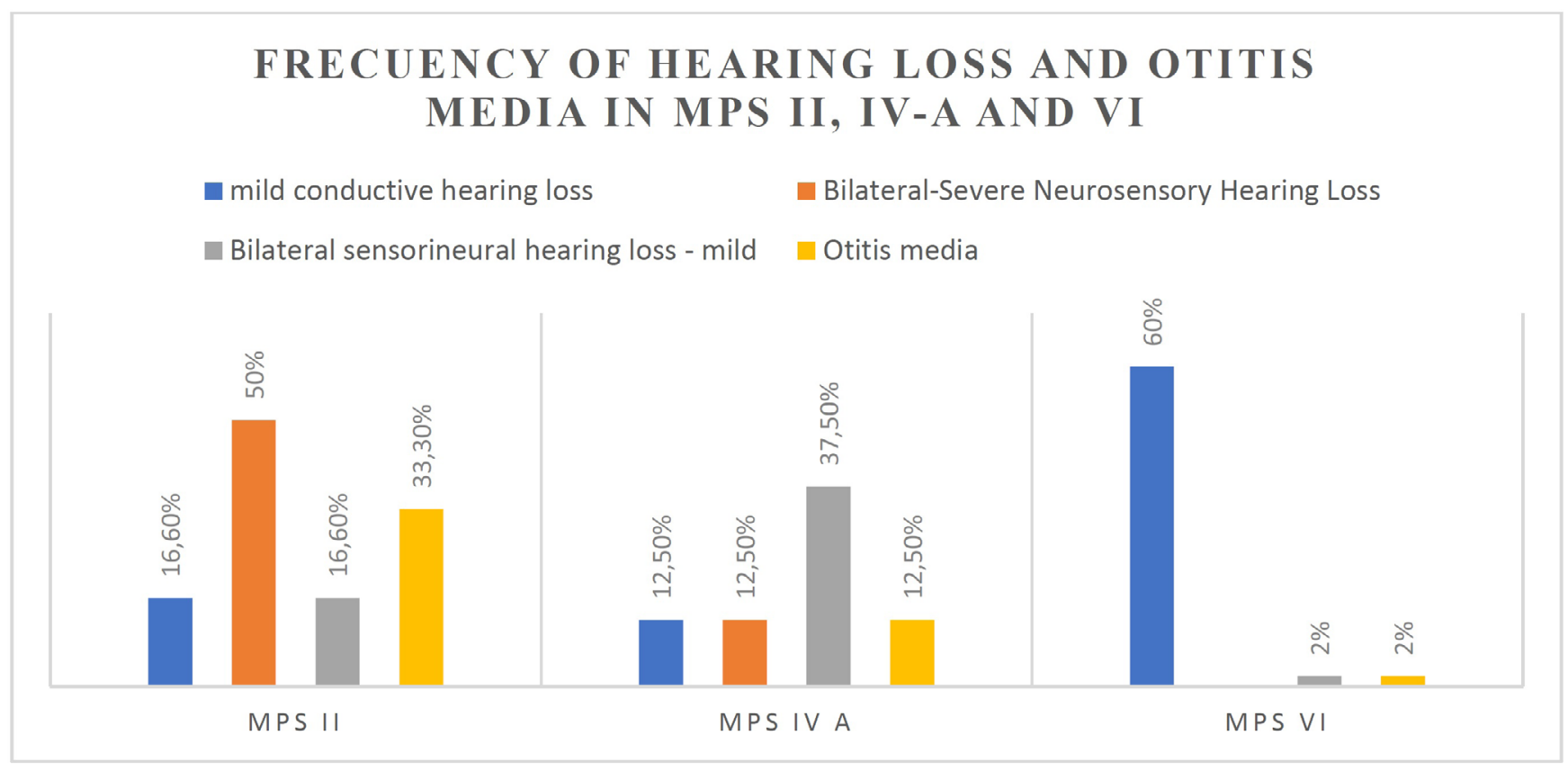

Figure 1. Frequency of Hearing Loss and Otitis Media in MPS II, IV-A and VI. The high frequency of Bilateral -Severe Neurosensory Hearing Loss in patients with MPS I, and the incidence of Mild Conductive hearing loss in patients with MPS.

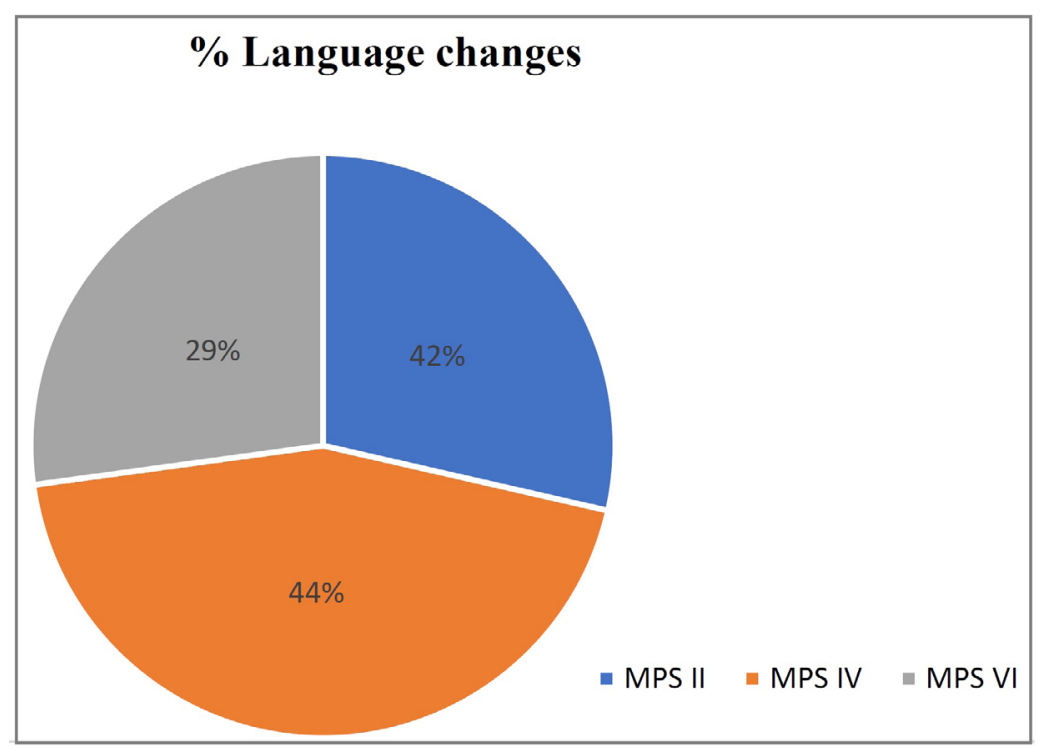

Figure 2. Percentage of changes in language. It is observed that that in MPS II and IV there is a higher percentage of change in language, compared to MPS VI, however it is important to take into account the number of participating patients for this mucopolysaccharidosis group. 
Table 2. Frequency of signs and symptoms in patients with MPS. It is observed that the greater number of affected has been diagnosed with Mild bilateral sensorineural hearing loss, obtaining a frequency of $31, \%$ of all patients. Tonsillar hypertrophy II was the diagnosis with the lowest frequency $(2.8 \%)$.

\section{OTORHINOLARYNGOLIC CHARACTERISTICS IN PATIENTS WITH MPS II, IV A AND VI}

\begin{tabular}{lcc}
\hline Characteristic & Number of affected (\#) & Frequency (\%) \\
\hline Short Neck & 6 & 17.1 \\
Tonsillar hypertrophy II & 3 & 8.5 \\
Tonsillar hypertrophy III & 1 & 2.8 \\
Turbinate hypertrophy & 4 & 11.42 \\
Mild conductive hearing loss & 6 & 17.14 \\
Mild bilateral sensorineural hearing loss & 11 & 31.4 \\
Severe bilateral sensorineural hearing loss & 6 & 17.1 \\
Mandibular Hypoplasia & 3 & 8.5 \\
Macroglossia & 2 & 5.7 \\
Acute Otitis Media & 2 & 5.7 \\
Chronic Otitis Media & 4 & 11.4 \\
Wide and depressed nasal bridge & 3 & 8.5 \\
Apnea-Hypopnea syndrome & 3 & 8.5 \\
\hline
\end{tabular}

Table 3. Colombian patients with different types of MPS and their relationship with hearing loss.

\begin{tabular}{|c|c|c|c|c|c|c|c|c|c|c|c|c|c|}
\hline \multirow{2}{*}{$\begin{array}{l}\text { TYPE OF } \\
\text { MPS }\end{array}$} & \multirow{2}{*}{ GENDER } & \multirow{2}{*}{ AGE } & \multicolumn{10}{|c|}{ DIAGNOSIS } & \multirow{2}{*}{$\begin{array}{l}\text { AUDIOLOGICAL } \\
\text { TREATMENT }\end{array}$} \\
\hline & & & BSH & MCH & ToH & OM & SN & TH & MH & OSAHS & WDN & MC & \\
\hline MPS II & $M$ & 6 & $x$ & & & & & $x$ & & & & & Hearing aids \\
\hline MPS II & M & 8 & & & & $x$ & & & & & & & \\
\hline MPS II & M & 15 & $x$ & & & & & & & & & & \\
\hline MPS II & $M$ & 16 & & & $x$ & & & & & & & & \\
\hline MPS II & $M$ & 28 & $x$ & & & $x$ & & & & & & & Hearing aids \\
\hline MPS II & $M$ & 35 & $x$ & & & & & & & & & $x$ & Hearing aids \\
\hline MPS IV A & $\mathrm{F}$ & 5 & & & & & & & $x$ & & $x$ & & \\
\hline MPS IV A & $\mathrm{F}$ & 6 & & & & & $x$ & & & & & & \\
\hline MPS IV A & M & 9 & & & & & $x$ & & & & & & \\
\hline MPS IV A & $M$ & 9 & $x$ & & & & & $x$ & & & & & \\
\hline MPS IV A & $M$ & 10 & $x$ & & & & & & & & & & \\
\hline MPS IV A & $M$ & 13 & & & & $x$ & $x$ & & & & & & \\
\hline MPS IV A & $\mathrm{F}$ & 16 & $x$ & & & & $x$ & $x$ & & & & & \\
\hline MPS IV A & $\mathrm{F}$ & 16 & & & & $x$ & & & & & & & \\
\hline MPS IV A & $\mathrm{F}$ & 17 & $x$ & & $x$ & & & & & & & & \\
\hline MPS IV A & $\mathrm{F}$ & 17 & & & & & & & $x$ & & $x$ & & \\
\hline MPS IV A & $M$ & 18 & $x$ & & & & & & & & & & \\
\hline MPS IV A & $M$ & 19 & $x$ & & & & & & & & & & Hearing aids \\
\hline MPS IV A & $M$ & 20 & $x$ & & & & & & & & & & \\
\hline MPS IV A & $M$ & 20 & $x$ & & & & & & & & & & \\
\hline MPS IV A & $\mathrm{F}$ & 20 & $x$ & & & & & & & & & & \\
\hline MPS IV A & $\mathrm{F}$ & 20 & & & & & & & & $x$ & & & \\
\hline MPS IV A & $M$ & 22 & $x$ & & & & & & & & & & \\
\hline MPS IV A & $\mathrm{F}$ & 24 & $x$ & $x$ & & & & & & & & & \\
\hline MPS IV A & $M$ & 25 & $x$ & & $x$ & & & & & & & & \\
\hline MPS IV A & $\mathrm{F}$ & 27 & $x$ & & & & & & & $x$ & & & Hearing aids \\
\hline MPS IV A & $M$ & 28 & $x$ & & & & & & & & & & \\
\hline MPS IV A & $M$ & 31 & & & & & & $x$ & & & & & \\
\hline MPS IV A & $\mathrm{F}$ & 33 & & & & & & & & $x$ & & & \\
\hline MPS IV A & $\mathrm{F}$ & 60 & $x$ & & $x$ & & & & & & & & Hearing aids \\
\hline MPS VI & $\mathrm{F}$ & 2 & & & & & $x$ & $x$ & & & & & \\
\hline MPS VI & $\mathrm{F}$ & 9 & & $x$ & $x$ & & & & & & & & \\
\hline MPS VI & $\mathrm{F}$ & 15 & & $x$ & & & $x$ & $x$ & & & & & \\
\hline MPS VI & $\mathrm{F}$ & 18 & & $x$ & & & & & & & & & \\
\hline MPS VI & $\mathrm{F}$ & 19 & $x$ & & & $x$ & & & & & & & Hearing aids \\
\hline
\end{tabular}

BSH : Bilateral Sensorineural Hearing Loss, MCH : Mild Conductive Hearing Loss, ToH : Tonsillar Hypertrophy, OM :Otitis media, SN : Short Neck, TH : Turbinate hypertrophy, MH: Mandibular Hipoplasia, OSAHS: Apnea-Hypopnea Syndrome, WDN: Wide and Depressed nasal Brigde, MC : Macroglossia 


\section{Mucopolysaccharidosis type II (Hunter syndrome)}

We reviewed six cases, all male, with an average age of 18 years (SD 10, 37 years). In the diagnosis of otorhinolaryngology, 5 patients were found to be affected by hearing loss $(83.3 \%)$, of these, 1 had conductive hearing loss (16.6\%), 3 had severe bilateral sensorineural hearing loss (50\%) and 1 (16.6\%) mild bilateral sensorineural hearing loss; of the latter, only 1 presented conditions due to macroglossia (MC). In addition, it was found that $33.3 \%$ of patients presented with OM (chronic and acute). $16 \%$ of the cases presented tonsillar hypertrophy III, as well as acute OM. For patients diagnosed with this type of MPS, at $50 \%$ ( 3 patients) the use of hearing aids was suggested as an audiological treatment.

\section{Mucopolysaccharidosis type IV A (Morquio syndrome)}

Twenty-four cases of patients with Morquio A syndrome were evaluated, of these, 12 were female and 12 male, with an average age of 20 years (SD 11, 25 years). In the diagnosis of otorhinolaryngology, 12 patients (50\%) were found who presented bilateral sensorineural hearing loss: 9 (37.5\%) had mild hearing failure and $3(12.5 \%)$ presented it severely. In addition, in 3 patients (12.5\%) OM was reported, 2 chronically and one acutely. Short nose and mandibular hypoplasia $(\mathrm{MH})$ were reported in 3 patients (12.5\%), mild conductive hearing loss in 3 of the patients (12.5\%), and 3 patients had a SN diagnosis. Finally, turbinate hypertrophy was reported in 3 patients $(8.3 \%)$ as well as OSAHS and tonsil II hypertrophy, detected by polysomnography test (Table1). In this case, the use of hearing aids was suggested as an audiological treatment for those patients who presented severe bilateral sensorineural hearing loss (12.5\%).

\section{Mucopolysaccharidosis type VI (Maroteaux Lamy syndrome)}

Five cases of patients with MPS VI were evaluated, all of them female, with an average age of 12.6 years ( 10.85 years). In the diagnosis of otorhinolaryngology it was found that $60 \%$ (3 patients) had mild bilateral conductive hearing loss, 2 patients (40\%) had both SN diagnosis and turbinates hypertrophy, 1 patient was reported with tonsillar hypertrophy II and a single patient (2\%) presented chronic OM and moderate bilateral sensorineural hearing loss, the latter being the only one that was suggested as an audiological treatment using hearing aids.

\section{Discussion}

Different researches around the world have reported levels of hearing loss in patients with MPS, demonstrating that when this condition occurs it is usually mixed, which includes diversity of conditions at the same time in the same patient. In general, hearing loss is usually attributed to problems associated with OM and eustachian tube dysfunction[25]; In addition, there has been talk of the loss of sensorineural hearing of unknown etiology, possibly due to the accumulation of GAGs, in the cochlear duct, cochlear nerve and vascular stria[4], which prevents its efficient functioning. Specifically, in Colombia there were no studies associated with hearing loss in patients with MPS, in this ways the problems associated with OM were found in $47.8 \%$ of the patients evaluated, which represents a considerable figure for this condition.

In previous studies conducted by Bicalho et al[26] Wold et al[27] and Vargas-Gamarra et al.[16], an increase in the prevalence of hearing loss is also reported in patients with different types of MPS; Likewise, studies realized by Santos in 2011 showed that children with MPS are at greater risk to develop bilateral sensorineural hearing loss, as well as the OSAHS[15] and may present more strongly as it progresses age; This allows us to explain the presence of hearing loss, whether mild, bilateral, severe or mild, in $60 \%$ of the patients evaluated in this study. On the other hand, the studies conducted by Gökdoğan in 2016, affirmed that the incidence of mixed hearing loss is related to age; Although conductive hearing loss is determined at early ages and in patients who were diagnosed early, it has been established that a mixed hearing loss can also be observed, and that this rate is between $33 \%$ and $71 \%$ of the cases. patients as age increases [28], this makes it possible to understand the fact of finding a more accurate and mixed diagnosis in elderly patients with respect to infants.

Specifically, our work found that approximately $66 \%$ of patients with MPS II had some type of conductive hearing loss. Investigations conducted by Keilmann et al (2011), determined that hearing loss is the most frequent experienced type of hearing loss in younger patients with MPS II and affirms that the majority of patients with MPS II have mixed hearing loss. Hearing loss was reported for $67 \%$, with a median age of onset of 4.8 years in Keilmann's studies.[14] Likewise, in studies conducted by Zanetti et al (2018) was found that hearing loss of cochlear type appeared in $77.8 \%$ of patients ( 82 patients /10 with MPS II).[29] This is related to the findings found in our research. Although hearing impairment does not directly contribute to mortality, hearing impairment does have significant contribution to development of speech and language, and quality of life[30], for this reason several authors have agreed that patients with MPS II need regular otolaryngological assessment because of the potential for progressive upper airway obstruction and obstructive sleep apnea, chronic or recurrent upper aerodigestive tract infections, and the prevalence of progressive hearing loss at an estimated rate of approximately $1 \mathrm{~dB}$ per year.[14,29]

On the other hand, we reported $62.5 \%$ of patients MPS IVA with BSH besides having diagnostic characteristics such as short stature, short neck, rough fascies.; although commonly reported hearing loss in MPS IVA is conductive in nature[30], sensorineural hearing loss has also been documented in some patients.[31] Riedner and Levin (1977)[18] reported that conductive hearing loss was observed in patient, but that mixed and sensorineural hearing loss were also found in older patients. Permanent hearing loss has not been observed until adolescence.[28] 
Nagao et al (2018) reported that 14 individuals with MPS IV (13 MPS IVA and 1 MPS IVB; aged between 12 and 38 years old) participated in the current study. They obtained auditory neurophysiological responses (auditory brainstem responses and otoacoustic emissions test) in addition to pure-tone audiometry and middle ear function tests (tympanometry and acoustic reflexes). The results indicated various levels and types of hearing loss with abnormal neurophysiological responses even in those patients with MPS IVA with normal pure tone thresholds. They found a strong relationship between height (short stature is an indicator of skeletal severity) and hearing sensitivity as well as a strong relationship between height and outer hair cell function in the inner ear (measured by otoacoustic emissions) among MPS IVA patients.[20] Their results indicated that the strong correlation between reduced height and hearing loss indicates that patients with severe skeletal dysplasia may be at higher risk of developing more severe hearing loss. More importantly, the spectrum of hearing disorders indicates that MPS IV patients should have annual neurophysiological hearing tests in addition to audiometric testing from an early age regardless of their skeletal severity to more carefully monitor disease progression[20].

Finally, $60 \%$ of the patients with MPS VI analyzed in this study presented $\mathrm{MCH}$ and other characteristics like $\mathrm{SN}$ and $\mathrm{TH}$. According to some authors, in the case of patients with MPS VI generally do not display any features of the condition at birth. They often begin to show signs and symptoms of MPS VI during early childhood. The features of MPS VI include macrocephaly, distinctive-looking facial features, and MC. The airway may become narrow in some patients with MPS VI, leading to frequent upper respiratory infections and short pauses in breathing during sleep. They may also have recurrent ear infections and hearing loss. Unlike other types of mucopolysaccharidosis, MPS VI does not affect intelligence[9,21].

Affected individuals may experience chronic watery, rhinorrhea, OM, hearing loss is common. Hearing loss may be due to failure of sound to be conducted from the outer ear trough the eardrum and tiny bones of the middle ear (conductive hearing loss) or may be due to damage to the inner ear or the nerves that transmit sound from the inner ear to the brain. In rare cases, hearing loss may be due to a combination of both problems (mixed hearing loss). [31,32,33]

We reported that $50 \%$ of MPS II ( 3 of 6 cases), $8 \%$ of patients with MPS type IV-A ( 2 of every 24 cases) and $20 \%$ of patients with MPS VI required adaptation of hearing aids during the review period; This, added to the percentage of patients who presented language disorders associated with tonsillar hypertrophy, $\mathrm{SN}$, turbinate hypertrophy, $\mathrm{MH}$, short nose and $\mathrm{MC}$, is an indirect sign of the impact of hearing loss on their development. However, the cognitive deficit associated with some of these patients must also be taken into account.[16] The hearing loss in patients with MPS is confirmed in our work as a prevalent finding that should be considered in the differential diagnosis of this population. The obstruction of the airway and the different set of otorhinolaryngological conditions allow us to indicate that patients with this pathology constitute a risk group, especially when dealing with the pediatric population

Generally, in patients with a diagnosis of MPS, the initiation of treatment in the early stages of development is of great importance in terms of the prognosis of the disease. However, due to the late onset of symptoms, the definitive diagnostic range is 3-4 years of age[28], so at ages lower than these, the findings of some level of hearing loss become more difficult to determine the condition correctly.

Furujo et al (2017) reported in an ERT follow-up that in patients with MPS IV the hearing improved after 36 months of therapy and 10 years later they had normal hearing $(20 \mathrm{~dB}$ for both ears). They conclude that the ERT was well tolerated and effective in preventing disease progression. although ERT is limited in terms of many other effects, which requires further investigation.[34]

Therefore, it is necessary to make a timely diagnosis, to provide an effective and personalized treatment based on the progress of the ERT, which has been shown to have positive effects on the development of the disease.

\section{Conclusion}

In this retrospective study, we found a high frequency and a progressive tendency to suffer audiological loss in patients with MPS II, IV-A and VI, highlighting the incidence of bilateral sensorineural hearing loss and OM. In the same way, taking into account the progression of the disease determined by age, a relationship between mixed hearing loss is proposed as age advances.

The early diagnosis of patients with MPS, as well as the development of audiological studies, allow us to approach a personalized medicine based on the initiation of an adequate ERT and the correct treatment of auditory disorders, improving the quality of life in the short and long term. In addition, the diagnosis and timely treatment generate a correct genetic counseling, educating parents, relatives and patients in the management of the disease and, therefore, having a positive impact on those affected.

\section{Limitations of the Study}

A history of audiological involvement is unknown, there are no controls - progression, only the data on admission to the comprehensive care program is described.

\section{Declaration of Conflicting Interests}

The author(s) declared no potential conflicts of interest with respect to the research, authorship, and/or publication of this article.

\section{Funding}

This study was carried out with its own funding resources. 


\section{References}

1. Stapleton M, Arunkumer N, Kubaski F, et al. Clinical presentation and diagnosis of the mucopolysacchariodoses. Mol Genet Metab. 2018;125(1-2):4-17. doi:10.1016/j. ymgme.2018.01.003

2. Couchman J, Pataki C. An Introduction to Proteoglycans and their localization. J Histochem Cytochem. 2012;60(12):885897. doi:10.1369/0022155412464638

3. Aspberg A. The Different Roles of Aggrecan Interaction Domains. J Histochem Cytochem. 2012;60(12):987-996. doi:10.1369/0022155412464376

4. Suarez-Guerrero J, Gómez Higuera P, Arias Flórez J, Contreras-García F. Mucopolysaccharidosis: clinical features, diagnosis and management. Rev Chil Pediatr. 2016;87(4):295-304. doi:10.1016/j.rchipe.2015.10.004

5. Leroux S, Muller JB, Boutaric E, et al. Hurler síndrome: early diagnosis and treatment. Arch Pediatr. 2014;21(5):501-506. doi:10.1016/j.arcped.2014.02.013

6. Gupta A, Uttarilli A, Dalal A, Girisha KM. Hunter syndrome with late age of presentation: clinical description of a case and review of the literature. BMJ Case Rep. 2015;2015:bcr2015209305. doi:10.1136/bcr-2015-209305

7. Andrade F, Aldámiz-Echevarría L, Llarena M, Couce ML. Sanfilippo syndrome: overall review. Pediatr Int. 2015;57(3):331-338. doi:10.1111/ped.12636

8. Hendriksz CJ, Berger KI, Giugliani R, et al. International guidelines for the management and treatment of Morquio A síndrome. Am J Med Genet. 2015;167(1):11-25. doi:10.1002/ ajmg.a.36833

9. Giraldo GA, Ayala-Ramírez P, Prieto JC, García-Robles R, Acosta JC. Molecular findings of Colombian patients with type VI mucopolysaccharidosis (Maroteaux-Lamy syndrome). Meta Gene. 2016;7:83-89. doi:10.1016/j. mgene.2015.12.004

10. Montaño AM, Lock-Hock N, Steiner RD, et al. Clinical course of sly syndrome (mucopolysaccharidosis type VII). J Med Genet. 2016;53(6):403-418. doi:10.1136/ jmedgenet-2015-103322

11. Kiykim E, Barut K, Cansever MS, et al. Screening Mucopolysaccharidosis Type IX in Patients with Juvenile Idiopathic Arthritis. JIMD Rep. 2016;25:21-24. doi:10.1007/8904_2015_467

12. Stapleton M, Kubaski F, Mason M, et al. Presentation and treatments for Mucopolysaccharidosis type II (MPS II; hunter syndrome). Expert Opin Orphan Drugs. 2017;5(4):295-307. doi:10.1080/21678707.2017.1296761
13. Fiuza A, Martins A, Moreira G, et al. The impact of laronidase treatment in otolaryngological manifestations of patients with mucopolysaccharidosis. Braz J Otorhinolaryngol. 2016;82(5):522-528. doi:10.1016/j.bjorl.2015.09.006

14. Keilmann A, Nakarat T, Bruce IA, Molter D, Malm G. Hearing loss in patients with mucopolysaccharidosis II: data from HOS - the Hunter Outcome Survey. J Inherit Metab Dis. 2012;35(2):343-353. doi:10.1007/s10545-011-9378-5

15. Santos S, López L, González L, Domínguez J. Hearing loss and airway problems in children with Mucopolysaccharidoses. Acta Otorrinolaringol Esp. 2011;62(6):411-417. doi:10.1016/j.otoeng.2011.05.003

16. Vargas-Gamarra $M$, de Paula-Vernetta C, Vitoria Miñana I, et al. Audiological Findings in Children With Mucopolysaccharidoses Type I-IV. Acta Otorrinolaringol Esp. 2017;68(5):262-268. doi:10.1016/j.otorri.2016.11.004

17. Cheng M, Verp T, Knutel J, et al. Mucopolysaccharidosis type VII as a cause of recurrent non-immnune hydrops fetalis. J Perinat Med. 2003;31(6):535-537. doi:10.1515/ jpm.2003.083

18. Riedner D, Levin LS. Hearing patterns in Morquio's syndrome (mucopolysaccharidosis IV). Arch Otolaryngol. 1977;103(9):518-520. doi:10.1001/ archotol.1977.00780260048003

19. Käsmann-Kellner B, Weindler J, Pfau B, Ruprecht K. Ocular changes in mucopolysaccharidosis IV A (Morquio A syndrome) and long-term results of perforating keratoplasty. Ophthalmologica. 1999;213(3):200-205. doi:10.1159/000027420

20. Nagao K, Morlet T, Haley E, et al. Neurophysiology of hearing in patients with mucopolysaccharidosis type IV. Mol Genet Metab. 2018;123(4):472-478. doi:10.1016/j. ymgme.2018.02.002

21. Shigematsu Y, Hori C, Nakai A, et al. Mucopolysaccharidosis VI (Maroteaux-Lamy syndrome) with hearing impairment and pupillary membrane remnants. Acta Paediatr Jpn. 1991;33(4):476-481. doi:10.1111/j.1442-200x.1991. tb02574.x

22. Fernanda HBTAV, Steiner CE, Correa J Neto, Boy R, Schwartz VD. Medical costs related to enzyme replacement therapy for mucopolysaccharidosis types I, II, and VI in Brazil: a multicenter study. Value Health Reg Issues. 2015;2015(8):99-106. doi:10.1016/j.vhri.2015.08.002

23. Amartino H, Arberas C, Azar N, et al. Guía para el diagnóstico, seguimiento y tratamiento de la mucopolisacaridosis de tipo II (MPS-II) o Enfermedad de Hunter. Arch Argent Pediatr. 2011;109(2):175-181. https:// www.sap.org.ar/docs/publicaciones/archivosarg/2011/ v109n2a21.pdf 
24. Jameson E, Jones S, Remmington T. Tratamiento de reemplazo enzimático con laronidasa para la mucopolisacaridosis tipo I (MPS I). Cochrane Db Syst Rev. 2019;6: cd009354. doi:10.1002/14651858.cd009354.pub5

25. Santos R, De oliveira V, Falcao A, Gomes T. Los efectos auditivos de mucopolisacaridosis. Paper presented at: $X$ Congreso de la Asociación Española de Audiología, Sevilla; 2013: 93-96

26. Bicalho C, Rezende M, Nogueira A, et al. The importance of the otorhinolaryngologic evaluation in mucopolysaccharidosis patients. Arq Int Otorrinolaringol. 2011;(15):290-294. doi:10.1590/S1809-48722011000300004

27. Wold S, Derkay C, Darrow D, Proud V. Role of the pediatric otolaryngologist in diagnosis and management of children with mucopolysaccharidoses. Int J Otolaryngol. 2010;74(1):27-31. doi:10.1016/j.ijporl.2009.09.042

28. Gökdoğan Ç, Altinyay Ş, Gökdoğan O, et al. Audiologic evaluations of children with mucopolysaccharidosis. Braz J Otorhinolaryngol. 2016;82(3):281-284. doi:10.1016/j. bjorl.2015.05.007

29. Zanetti D, Vezzani M, Di Berardino F, et al. Characterization of Hearing Loss in Children With Mucopolysaccharidosis. In: Hatzopoulos S, Ciorba A, eds. An Excursus into Hearing
Loss. London, United Kingdon: Intech Open; 2018: 55-70. doi:10.5772/intechopen.74196

30. Giugliani R, Harmatz P, Wraith J. Management guidelines for mucopolysaccharidosis VI. Pediatrics. 2007;120(2):405418. doi:10.1542/peds.2006-2184

31. Ruckenstein M, Macdonald R, Clarke J, Forte V. The management of otolaryngological problems in the mucopolysaccharidoses: a retrospective review. $J$ Otolaryngol. 1991;(20):177-183.

32. Hendriksz C, Al-Jawad M, Berger K, et al. Clinical overview and treatment options for non-skeletal manifestations of mucopolysaccharidosis type IVA. J Inherit Metab Dis. 2013;36(2):309-322. doi:10.1007/s10545-012-9459-0

33. Brands MM, Oussoren E, Ruijter GJ, et al. Up to five years experience with 11 mucopolysaccharidosis type VI patients. Mol Genet Metab. 2013;109(1):70-76. doi:10.1016/j. ymgme.2013.02.013

34. Furujo M, Kosuga M, Okuyama T. Enzyme replacement therapy attenuates disease progression in two Japanese siblings with mucopolysaccharidosis type VI: 10-Year follow up. Mol Genet Metab Rep. 2017;13:69-75. doi:10.1016/j. ymgmr.2017.08.007 